\title{
Deficiency of Vitamin D in HIV Infected Patients and Its Effect on Some of the Immunological Parameters
}

\author{
Nina Yancheva1, Ivaylo Elenkov¹, Tatyana Tchervenyakova1, Ivanka Gabarska1, \\ Georgi Kirilov', Maria Nikolova ${ }^{3}$, Marina Alexandrova ${ }^{3}$ \\ ${ }^{1}$ Department for Patients with Acquired Immune Deficiency, Specialized Hospital for Infectious and Parasitic \\ Diseases, Sofia, Bulgaria \\ ${ }^{2}$ Clinical Center of Endocrinology and Gerontology, Sofia, Bulgaria \\ ${ }^{3}$ National Reference Laboratory of Immunology of the National Center of Infectious and Parasitic Diseases, \\ Sofia, Bulgaria \\ Email: dr.yancheva@abv.bg
}

Received 14 June 2015; accepted 4 September 2015; published 7 September 2015

Copyright (C) 2015 by authors and Scientific Research Publishing Inc.

This work is licensed under the Creative Commons Attribution International License (CC BY). http://creativecommons.org/licenses/by/4.0/

(c) (i) Open Access

\section{Abstract}

Today the HIV infection is a chronic disease with significantly longer duration of the life of the patients. Problems of pressing interest are the persistent immune activation and chronic inflammation during the treatment with antiretroviral therapy. Taking this into account, different factors which could affect the immune system and the progress of the HIV infection are being researched. Vitamin D (25(OH)D) is one of those factors if we take note of its effect on the innate and acquired immunity. The aim of this study was to assess 25 -hydroxyvitamin D (vitamin D) status in one part of the Bulgarian HIV-infected adult population and to assess connection between 25-hydroxyvitamin D (vitamin D) status and plasma levels of some major cytokines (IL-2, IL-4, IL-6, IL-10, TNF- $\alpha$ and IFN- $\gamma$ ). The study includes 145 HIV-positive patients, who are being monitored in the Department for acquired immune deficiency at Specialized Hospital for Infectious and Parasitic Diseases "Proff. Ivan Kirov"-Sofia. From all of the monitored patients only in $15 \%$ of the tested we found normal 25(OH)D serum levels, and in $12 \%$ of the patients we found deficiency. The largest group is that of patients with insufficiency of vitamin $D$. We didn't discovered significant difference in the 25(OH)D average values between men and women. There were no significant differences in the average values of the $25(\mathrm{OH}) \mathrm{D}$ serum levels when dividing the patients according to their antiretroviral therapy, but after separating the patients by gender, we found that the untreated women had average values of 25(OH)D higher than that of the women treated with EFV. On the next stage of the survey on the $60 \mathrm{HIV}$-infected patients, who are from the first tested group, we additionally defined the cytokine profile. Our results suggests that increasing 25(OH)D deficiency worsens the damaging of the cellular immune response. The lower levels of vitamin Dare associated with in- 
creased levels of IL-6, decreased levels of IL-10, IFN- $\gamma$ and TNF- $\alpha$. There's active immune inflammation when there are reduced 25(OH)D serum levels and it leads to stimulated secretion of the regulatory cytokines and suppression of the Th1 antiviral response. The phase of advanced 25(OH)D deficiency is characterized by parallel depletion of the regulatory and effecter capabilities of CD4 lymphocytes. The recovery of the CD4 lymphocyte pool is difficult because of the lower than average 25(OH)D serum levels, regardless of the conducted antiretroviral therapy.

\section{Keywords}

HIV, Vitamin D, Deficiency, Cytokines, Immune Activation

\section{Introduction}

Today the HIV infection has turned into a chronic disease with significantly longer duration of the life of the patients, as long as they maintain a suitable antiretroviral therapy. Problems of pressing interest are the persistent immune activation and chronic inflammation during the treatment with antiretroviral therapy. Taking this into account, different factors which could affect the immune system and the progress of the HIV infection are being researched. Vitamin D (25(OH)D) is one of those factors if we take note of its effect on the innate and acquired immunity [1]. Vitamin D is a generic name which is used to indicate vitamin D2 (ergocalciferol) and vitamin D3 (cholecalciferol). It is labeled as 25(OH)D. In order to show its functions, vitamin D interacts with a corresponding receptor (VDR), which is expressed by a large number of organs including brain, muscle, pancreas, colon, mammary glands and immune cells. Many researches explain the role of vitamin D as an important mediator of the congenital and acquired immune responses [2].

Numerous international studies analyze the serum levels of 25(OH)D for HIV-infected patients, and the results show that those patients have insufficiency and deficiency more frequently [3]. The evaluation of the risk factors for the hypovitaminosis D for the HIV infection includes evaluation of the HIV-specific and HIV-independent risk factors. Some risk factors as the female sex, winter season, age, diet with a lower intake of vitamin $\mathrm{D}$ and a darker skin color are similar risk factors to those reported from the HIV-negative cohorts. Risk factors related to HIV-infection are increased turnover of the T-lymphocytes, chronic inflammation, increased TNF- $\alpha$ and the conducted antiretroviral therapy [4] [5]. The antiretroviral drugs which are proven to affect the metabolism of 25(OH)D are the protease inhibitors and the non-nucleoside inhibitor Efavirenz (EFV). The protease inhibitors inhibit 25(OH)D $1 \alpha$-and 25 $\alpha$-hydroxylation in the hepatocytic and monocytic cell lines. The Efavirenz (EFV) leads to reduction of the 25(OH)D catabolism, via induction of CYP24 and a decrease of the transcription from one 25-hydroxylase-CYP2R [5].

It's a fact that the antiretroviral therapy induces not only the quantitative, but also the qualitative changes of the cytokine profile of the patients infected with HIV [6] [7]. That requires seeking new opportunities for a permanent decrease of the immune activation and the chronic inflammation. Progression towards HIV and the death rates could be reduced, together with the suitable virus suppression. The connection between the 25(OH)D serum levels and the cytokine profile could also affect the development of the HIV infection [7]-[10]. The biological effect of the cytokines depends on their interactions. More researches of the inflammatory and regulatory profiles are necessary in order to clarify the interactions between the cytokine levels and the actual clinical condition of the HIV-infected, especially those with prolonged use of a combined ART [6] [7]. The aim of this study was to assess vitamin D status in Bulgarian HIV-infected adult population and to assess connection between 25-hydroxyvitamin D status and plasma levels of some major cytokines.

\section{Materials and Methods}

This was an observational, analytical study, which included 145 HIV-positive patients, who are followed at the Department for acquired immune deficiency at Specialized Hospital for Infectious and Parasitic Diseases "Proff. Ivan Kirov"-Sofia city.

Data were collected through a form containing sociodemographic, immune-virological, antiretroviral therapy, vitamin $\mathrm{D}$ and cytokine profile. 
A specialized test of the 25(OH)D serum level was conducted and the blood samples were collected in the months of November to March. The winter months were chosen intentionally in order to limit the impact of the sun light upon 25(OH)D serum level. The 25(OH)D (25OHD total) serum level of all of the tested patients at first was determined by a highly sensitive and specific radioimmunoassay kit (25OH Vitamin D total-RIA-CT, DIA source Immuno Assays, Belgium). According to the reference values of the method, 25(OH)D $<10 \mathrm{ng} / \mathrm{ml}$ levels are defined as a deficiency and the serum levels between $10-30 \mathrm{ng} / \mathrm{ml}$ are defined as insufficiency. It's sufficient if the level of 25(OH)D is from 30 to $150 \mathrm{ng} / \mathrm{ml}$.

On the next stage of the survey on the 60 HIV-infected patients, who are from the first tested group, additionally defined the cytokine profile. In order to analyze the effects of the 25(OH)D serum level upon the cytokine profile we once again tested the 25(OH)D serum levels of those patients. The blood samples of those who were tests were collected in the months August-November. The test VIDAS ${ }^{\circledR} 25 \mathrm{OH}$ Vitamin D Total was used-enzyme immunoassay with highly fluorescent measurement ELFA. According to the reference values of this method the $25(\mathrm{OH}) \mathrm{D}<20 \mathrm{ng} / \mathrm{ml}$ serum levels are considered as deficiency and the serum levels between 20 - 30 $\mathrm{ng} / \mathrm{ml}$ are defined as insufficiency. It's sufficient if the level of 25(OH)D is 30 to $100 \mathrm{ng} / \mathrm{ml}$.

To determine the cytokine profile of those patients, the test "Human Th1/Th2 Cytokine Kit" BD ${ }^{\mathrm{TM}}$ CBA was used. In one tube, IL-2, IL-4, IL-6, IL-10, TNF- $\alpha$ and IFN- $\gamma$ can be quantified simultaneously. The kit is optimized to perform quantitative analysis of the cytokines in supernatants from tissue cultures, plasma collected in a container with EDTA or serum samples.

Data were collected only after the Ethics Committee of Specialized Hospital for Infectious and Parasitic Diseases "Proff. Ivan Kirov" has approved the study.

All results are expressed as mean and standard deviation, and submitted to Kolmogorov Smirnov and Lillieforsnormality tests. Comparing the groups using Mann-Whitney Utest and one factor statistical analysis ANOVA. The test is considered statistically significant if $\mathrm{p}<0.05$.

\section{Results}

The distribution of the patients according to their gender-respectively 108 male and 37 female. The average overall age of the tested subjects is $34.9 \pm 9.3$ years. The average age of the males is $34.8 \pm 9.2$ years and that of the females is $35.2 \pm 9.5$.

The patients are being monitored ambulatory; they did not have any indications for hospitalization. In the test group, bigger part of the patients is treated with the antiretroviral therapy, but there are also naive patients.

From all of the followed patients only in $15 \%$ of the tested $(n=22)$ we found normal vitamin $D$ serum levels. Accordingly, for the other $85 \%(\mathrm{n}=123)$ we discovered $25(\mathrm{OH}) \mathrm{D}<30 \mathrm{ng} / \mathrm{ml}$ serum levels. From them $12 \%$ $(\mathrm{n}=17)$ the $25(\mathrm{OH}) \mathrm{D}$ serum level is $<10 \mathrm{ng} / \mathrm{ml}$, which defines as deficiency of Vitamin $\mathrm{D}$. The largest group is that of patients with 25(OH)D level between $10-30 \mathrm{ng} / \mathrm{ml}-73 \%(n=105)$. Those serum levels are defined as insufficiency of vitamin D.

We didn't discovered significant difference in the 25(OH)D average values between men and women $(\mathrm{p}=$ $0.85)$. From the tested women $83 \%(\mathrm{n}=31)$ have values of $25(\mathrm{OH}) \mathrm{D}$ below $30 \mathrm{ng} / \mathrm{ml}$. The tested men $83.3 \%$ $(n=90)$ had deficiency or insufficiency of 25(OH)D.

The distribution of patients according to their gender and the values of 25(OH)D is shown in Table 1.

There were no significant differences between the average values of 25(OH)D of the male and female patients and in the individual groups defined as deficiency, insufficiency and sufficient levels of vitamin D. There were no significant differences in the average values of the 25(OH)D serum levels when dividing the patients according to intake and their type antiretroviral therapy in 4 groups (naïve patients, treated with protease inhibitors,

Table 1. Distribution of patients according to 25(OH)D levels.

\begin{tabular}{cccccccc}
\hline & \multicolumn{2}{c}{ Deficiency } & \multicolumn{2}{c}{ Insufficiency } & \multicolumn{2}{c}{ Sufficient } \\
\cline { 2 - 6 } Vitamin D & $\mathrm{n}$ & $\%$ & $\mathrm{n}$ & $\%$ & $\mathrm{n}$ & $\%$ & 0.8 \\
Male & 10 & 9.2 & 80 & 74 & 18 & 16.8 \\
Female & 3 & 8.1 & 28 & 75.6 & 6 & 16.3 \\
\hline
\end{tabular}


treated with Efavirenz and treated with Nevirapine). After separating the patients by gender, there was a statistically significant association with the 25(OH)D level and the conducted treatment only in women. The untreated women had average values of 25(OH)D higher than the women treated with $\mathrm{EFV}(\mathrm{p}=0.026746)$. The average value of $25(\mathrm{OH}) \mathrm{D}$ in the untreated women was significantly higher than that of the untreated men $(\mathrm{p}=$ $0.0257432)$.

After a re-examination of 25(OH)D (60 patients from the group, parallel with cytokine profile), although the blood samples were collected between the summer and autumn months, we once again found that a big part from the patients have deficiency or insufficiency. From the tested patients $81.6 \%(\mathrm{n}=49)$ were with 25(OH)D values lower than the normal, and for $41.6 \%(n=25)$ of them we discovered deficiency, and for $40 \%(n=24)$ of them we discovered insufficiency. Only $18.4 \%(n=11)$ of the patients had normal $25(\mathrm{OH}) \mathrm{D}$ values.

Second stage of our research was determining the cytokine profile of some of our monitored patients. Except the examined and analyzed up to this moment date results, 60 of the patients had the following cytokines examined: IL-2, IL-4, IL-10, IL-6, TNF- $\alpha$ and IFN- $\gamma$. 30 of the patients (20 male and 10 female) had determined cytokine profile ex vivo (concentration of the cytokines IFN $\gamma$, TNF $\alpha$, IL-2, IL-4, IL-6, IL-10 in the peripheral blood). All of the patients in the subgroup are on a different stage since the start of the antiretroviral therapyaccordingly 3 to 185 months. For convenience we defined them as group A. For the remaining 30 patients (21 male and 9 female) the cytokine "potential" was determined-meaning that the concentration of cytokines after an unspecific stimulation on a sample of peripheral blood with phytohaemagglutinin. Those are the patients from subgroup B. In this subgroup two of the patients are not treated, the rest are on different stages of the treatment-2 to 153 months from the start of the treatment. We didn't discovered statistically significant difference between the average number of CD4 cells in the three subgroups of patients with different 25(OH)D levels. There wasn't a statistically significant difference in the three groups of patients with different 25(OH)D levels regarding the CD4/CD8 index. The patients with lower 25(OH)D levels have lower CD4/CD8, even if the difference isn't statistically significant (Figure 1).

All patients with active virus replication are in the groups with abnormal 25(OH)D level (deficiency and insufficiency), even though a statistically significant difference wasn't discovered in the different groups.

Because the analyzed patients differ according to the duration of the antiretroviral therapy it is more correctly to compare the speed of the CD4 change, the difference between the baseline and the current number of CD4, divided by the months of therapy (Figure 2).

It was found that the patients with values of $25(\mathrm{OH}) \mathrm{D}<20 \mathrm{ng} / \mathrm{ml}$ recover the number of CD4 cells slower that of those patients with deficiency (20 - $30 \mathrm{ng} / \mathrm{ml}$ ) or normal 25(OH)D values (mean cells/ $/ \mathrm{l} / \mathrm{months:} \mathrm{6;} \mathrm{16;}$ $17 ; \mathrm{p}=0.009$ and 0.03 ).

Testing the cytokine profile without stimulation (subgroup A) gave the following results:

Comparing the groups according to the $25(\mathrm{OH}) \mathrm{D}$ serum values in terms of the cytokine profile showed that:

\section{CD4 in Vit D groups}

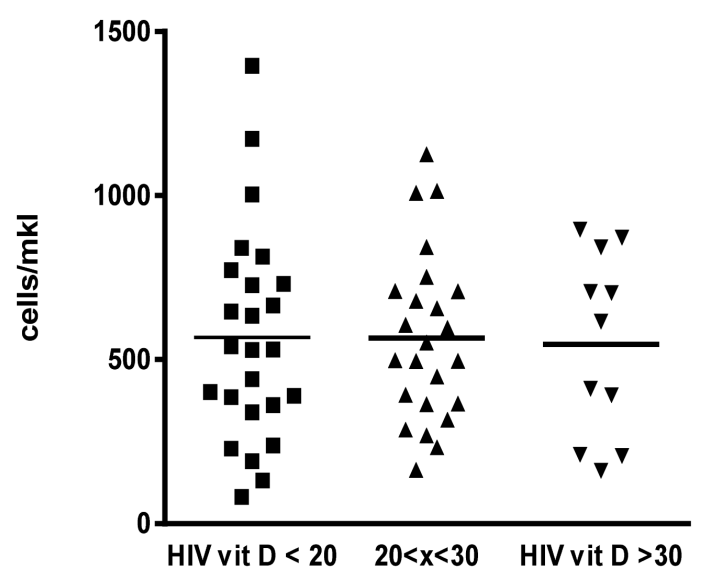

\section{CD4/CD8 in Vit D groups}

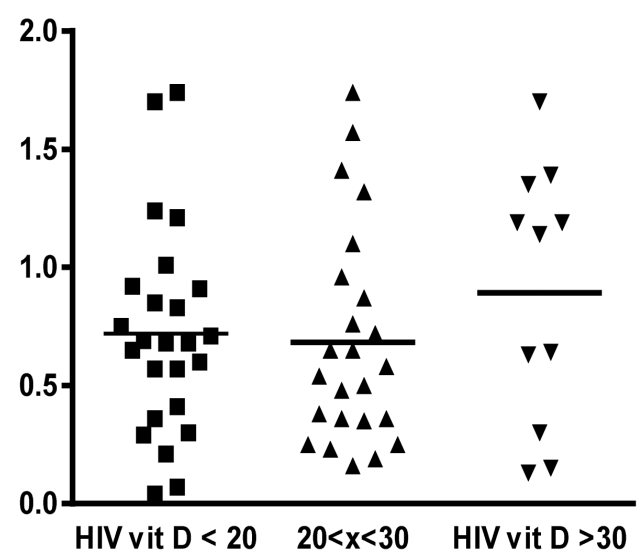

Figure 1. Distribution of values of the CD4 cells and index CD4/CD8 in the groups with different 25(OH)D levels. 

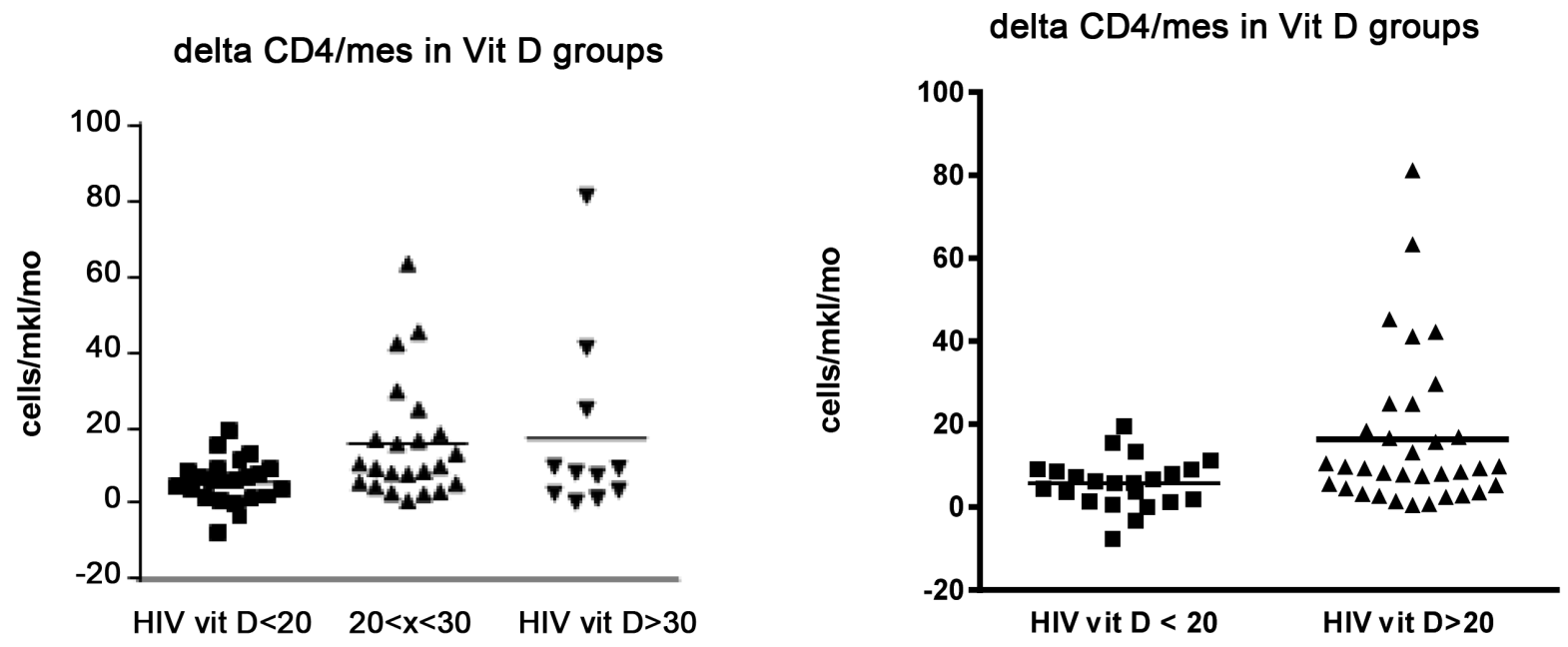

Figure 2. Recovering the number of CD4 cells depending on the 25(OH)D serum levels.

- IL-10 levels are reduced in patients with 25(OH) D deficiency compared to those with insufficiency (1, 2 vs. $1.6 \mathrm{p}=0.0265)$.

- The levels of the other cytokines do not differ significantly between the groups of 25(OH)D ( $>0.05)$.

- There's no difference in the ratios IFN- $\gamma / \mathrm{IL}-4$ and IFN- $\gamma / \mathrm{IL}-10$ reflecting the nature (power and regulation) of the Th1 immune response ( $p>0.05)$.

It was of interest to find what are the characteristics of the patients with very low and very high IFN- $\gamma$ expression and that's why a more detailed analyze was made in those two groups.

One of the subgroups includes 12 patients with very low IFN- $\gamma$ (mean $<2.1 \mathrm{pg} / \mathrm{ml}$ ). In the other subgroup that has 18 patients the average IFN $-\gamma$ value that was measured was above the upper referent limit (mean $>56 \mathrm{pg} / \mathrm{ml}$ ). It was discovered that those two subgroups differ significantly in number of the CD4 cells, the IL-4 level and the IFN- $\gamma /$ IL-4 ratio. The subgroup with high IFN- $\gamma$ has significantly higher CD4 cells than the average value and a lower than the average IL-4 values, compared to the group with low IFN- $\gamma$. The subgroup with high IFN- $\gamma$ is with a higher ratio IFN- $\gamma / \mathrm{IL}-4$, which shows the power of the Th1 immune response (Figure 3). Significant differences between those two groups regarding IL-6, IL-10 и TNF- $\alpha$ were not found. Significant differences between the 25(OH)D serum levels, the virus load and the CD4/CD8 index were not found.

A connection between the 25(OH)D serum level was found only in the subgroups with lower values of IFN- $\gamma$ and the plasma levels of IL-6, IL-10 and the ratio IFN- $\gamma / \mathrm{IL}-4$ (Th1/Th2):

- Patients with 25(OH)D insufficiency and deficiency are characterized by higher IL-6 levels compared to patients who have normal 25(OH)D values (mean $=1 ; 1 ; 0.88 ; \mathrm{p}=0.04$ ).

- Patients with 25(OH)D deficiency have lower IL-10 levels compared to patients with normal levels (mean $1.3 ; 1.7 ; 1.3 ; \mathrm{p}=0.03$ ).

- IFN- $\gamma / \mathrm{IL}-4$ index is lower with patients who have 25(OH)D deficiency (mean 45 vs. 71 and $62 ; \mathrm{p}=0.035$ ).

The study of the cytokine profile after a stimulation with phytohaemaglutinin (subgroup B) gave the following results:

In this subgroup we compared patients with 25(OH)D $<20 \mathrm{ng} / \mathrm{ml}$ serum level and patients with values above $>20 \mathrm{ng} / \mathrm{ml}$, because of the due to the small number of patients $(\mathrm{n}=2)$ with normal $25(\mathrm{OH}) \mathrm{D}(>30 \mathrm{ng} / \mathrm{ml})$ values.

Analyses showed that the IL-10 level is reduced significant in patients with vitamin D serum levels $<20 \mathrm{ng} / \mathrm{ml}$ compared to those with serum levels $>20 \mathrm{ng} / \mathrm{ml}$ (mean $=134$ and 196; $\mathrm{p}=0.05$ ).

We found significant difference for the TNF- $\alpha$ plasma level. It's decreased significantly in patients with $25(\mathrm{OH}) \mathrm{D}$ deficiency compared to the group with serum level $>20 \mathrm{ng} / \mathrm{ml}$ (mean $<20=978 ;>20=2125 ; \mathrm{p}=$ 0.027).

We also found statistically significant differences in the IL-6 average values depending on the 25(OH)D serum level. Patients with 25(OH)D deficiency have lower IL-6 values compared to patients without deficiency (mean 22025 и 29835; p = 0.02). 


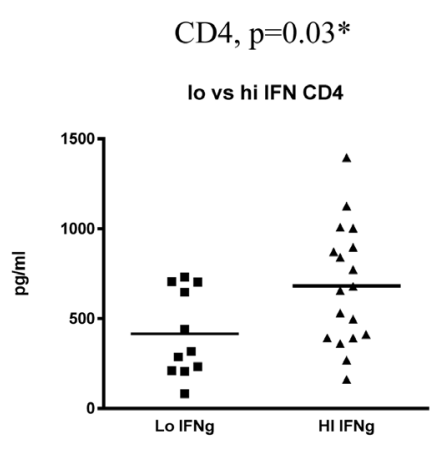

Low IFN- $y$

414.8
High IFN- $y$

681.4

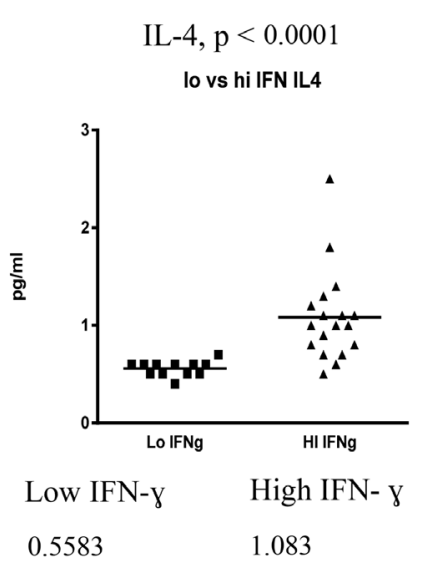

Ratio IFN- $\mathrm{\gamma} / \mathrm{IL} 4, \mathrm{p}<0,0001 * * * *$

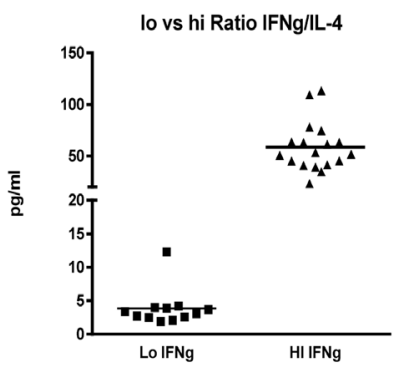

Low IFN- y High IFN- y

$3.867 \quad 58.54$

Figure 3. The difference in the number of CD4, IL-4 and IFN- $\gamma / \mathrm{IL}-4$ between the two subgroups with low and high IFN- $\gamma$.

Statistically significant difference between the groups based on the INF- $\gamma$, IL-2 and IL-4 levels was not found $(\mathrm{p}>0.05)$. There is no difference in the ratio INF- $\gamma / \mathrm{IL}-10$, despite the difference in the IL-10 levels.

But we discovered that the INF- $\gamma / \mathrm{IL}-4$ ratio which reflecting the strength of Th1 immune response is significantly higher for patients with 25(OH)D > $20 \mathrm{ng} / \mathrm{ml}$ values compared to patients with deficiency (mean $111 \mathrm{vs.}$ 22; $\mathrm{p}=0.0124$ ).

Similarly, in the results in subgroup A and in subgroup B were not found significant differences in terms of the CD4 number and CD4/CD8 index. There is a tendency for a higher CD4 number with patients with $25(\mathrm{OH}) \mathrm{D}>20 \mathrm{ng} / \mathrm{ml}$ values.

\section{Discussion}

In vitro researches show that the vitamin D serum levels have impact on the cytokine profile in the organism-it inhibits the production of the IFN- $\gamma$ and IL-6 [11]. The in vivo researches are scarce and have produced conflicting results. A research including 28 healthy adults, performed by Barker et al. [3], concludes that 25(OH)D serum levels have inversely proportional correlation with the IFN- $\gamma$ levels but not with the TNF- $\alpha$ or IL-10 levels. The results from a research conducted by Peterson [12] are opposing those of Barker's. After testing the serum levels of 69 females, the results showed that there was a inversely proportional dependence between the 25(OH)D serum levels and the TNF- $\alpha$ serum levels. There wasn't such correlation between the IL-6 or IL-10 serum levels. In our study we found that the TNF- $\alpha$ plasma level decreased significantly in patients with 25(OH)D deficiency compared to the group with serum level $>20 \mathrm{ng} / \mathrm{ml}$.

Ansemant et al. [1] reported data from a research including $263 \mathrm{HIV-infected} \mathrm{patients} \mathrm{treated} \mathrm{with} \mathrm{the} \mathrm{antire-}$ troviral therapy according to which there is a significant positive association between severe deficiency of increased 25(OH)D plasma levels of the IL-6 and they don't established any association with the duration and type of therapy. In the present study patients with 25(OH)D insufficiency and deficiency are characterized by higher IL-6 levels compared to patients who have normal 25(OH)D.

Some researches demonstrate that 25(OH)D plays an important role in the IL-10 production. According to Khoo et al. [13], 25(OH)D directly affects the Treg cell growth and stimulates the production of IL-10. In our study we found that patients with 25(OH)D deficiency have lower IL-10 levels compared to patients with normal levels.

Giacomet et al. [14] presented that the supplementation with 25(OH)D doesn't have an effect on the values of the CD4 cells, but it's connected with the decrease in the ratio Th 17:Treg immune response after 3 months. In the present study was found that the patients with values of 25(OH)D $<20 \mathrm{ng} / \mathrm{ml}$ recover the number of CD4 cells slower that of those patients with 25(OH)D levels $>20 \mathrm{ng} / \mathrm{ml}$.

\section{Conclusion}

In conditions of chronic HIV infection the increasing 25(OH)D deficiency worsens the damaging of the cellular immune response. Our results confirm the researches of other scientists. There's active immune inflammation when there are reduced vitamin D serum levels and it leads to stimulated secretion of the regulatory cytokines 
and suppression of the Th1 antiviral response. The phase of advanced 25(OH)D deficiency is characterized by parallel depletion of the regulatory and effecter capabilities of CD4 lymphocytes. The recovery of the CD4 lymphocyte pool is difficult because of the lower than average 25(OH)D serum levels, regardless of the conducted antiretroviral therapy. The compensation of this deficiency may improve the effect of the specific therapy and recovery of the protective cellular immunity.

\section{Acknowledgements}

This study was made thanks to project: Grant 2014 of Medical University-Sofia and by financial support of the pharmaceutical company MSD.

\section{Conflict of Interests}

The authors declare no interest conflicts.

\section{References}

[1] Ansenmant, T., Mahy, S., Piroth C., et al. (2013) Severe Hypovitaminosis D Correlates with Increased Inflammatory Markers in HIV Infected Patients. BMC Infectious Diseases, 13, 7. http://dx.doi.org/10.1186/1471-2334-13-7

[2] Cozzi-Lepri, A., French, M., Baxter, J., et al. (2011) Resumption of HIV Replication Is Associated with Monocyte/ Macrophage Derived Cytokine and Chemokine Changes: Results from a Large International Clinical Trial. AIDS, 25, 1207-1217. http://dx.doi.org/10.1097/QAD.0b013e3283471f10

[3] Barker, T., Martins, T., Hill, H., et al. (2013) Circulating Pro-Inflammatory Cytokines Are Elevated and Peak Power Output Correlates with 25-Hydroxyvitamin D in Vitamin D Insufficient Adults. European Journal of Applied Physiology, 113, 1523-1534. http://dx.doi.org/10.1007/s00421-012-2582-7

[4] Barbosa, N., Costa, L., Pinto, M., et al. (2014) Vitamin D and HIV Infection: A Systematic Review. Journal of Immunodeficiency \& Disorders, 3, 1.

[5] Pinzone, M., DiRosa, M., Malaguarnera, M., Madeddu, D., et al. (2013) Vitamin D Deficiency in HIV Infection: An Underestimated and Undertreated Epidemic. European Review for Medical and Pharmacological Sciences, 17, 12181232.

[6] Regidor, D., Detels, R., Breen, E., Widney, D., et al. (2011) Effect of Highly Active Antiretroviral Therapy on Biomarkers of B-Lymphocyte Activation and Inflammation. AIDS, 25, 303-314. http://dx.doi.org/10.1097/QAD.0b013e32834273ad

[7] Shepherd, L., Souberbielle, J., Bastard, J., et al. (2014) EuroSIDA in EuroCOORD. Prognostic Value of Vitamin D Level for All-Cause Mortality, and Association with Inflammatory Markers, in HIV-INFECTED Persons. The Journal of Infectious Diseases, 210, 234-243. http://dx.doi.org/10.1093/infdis/jiu074

[8] Meira, D.A., Almeida, R.A.M.B., Barbosa, N.A., Souza, L.R., Olivo, T.E.T., Henriques, R.M.S., et al. (2008) Assessment of Cytokine Values in Serum by RT-PCR in HIV-1 Infected Individuals with and without Highly Active Anti-Retroviral Therapy (HAART). Journal of Venomous Animals and Toxins including Tropical Diseases, 14, 685-702. http://dx.doi.org/10.1590/S1678-91992008000400011

[9] Ross, A., Judd, S., Ziegler, T., et al. (2012) Risk Factors for Vitamin D Deficiency and Relationship with Cardiac Biomarkers, Inflammation, and Immune Restoration in HIV-Infected Youth. Antiviral Therapy, 17, 1069-1078. http://dx.doi.org/10.3851/IMP2318

[10] Yusupov, E., Li-Ng, M., Pollack, S., Yeh, J., Mikhail, M. and Aloia, J. (2010) Vitamin D and Serum Cytokines in a Randomized Clinical Trial. International Journal of Endocrinology, 2010, Article ID: 305054.

[11] Yuzefpolskiy, Y., Baumann, F., Penny, L., Studzinski, G., Kalia, V. and Sarkar, S. (2014) Vitamin D Receptor Signals Regulate Effector and Memory CD8 T Cell Responses to Infections in Mice. Journal of Nutrition, 144, $2073-2082$. http://dx.doi.org/10.3945/jn.114.202895

[12] Peterson, C. and Heffernan, M. (2008) Serum Tumor Necrosis Factor- $\alpha$ Concentrations Are Negatively Correlated with Serum 25(OH)D Concentrations in Healthy Women. Journal of Inflammation, 5, 10. http://dx.doi.org/10.1186/1476-9255-5-10

[13] Khoo, A., Chai, L., Koenen, H., Sweep, F., et al. (2011) Regulation of Cytokine Responses by Seasonality of Vitamin D Status in Healthy Individuals. Clinical \& Experimental Immunology, 164, 72-79. http://dx.doi.org/10.1111/j.1365-2249.2010.04315.x

[14] Giacomet, V., Vigano, A., Manfredini, V., et al. (2013) Cholecalciferol Supplementation in HIV-Infected Youth with Vitamin D Insufficiency: Effects on Vitamin D Status and T-Cell Phenotype: A Randomized Controlled Trial. HIV Clinical Trials, 14, 51-60. http://dx.doi.org/10.1310/hct1402-51 